\title{
Delayed association of the NADPH oxidase complex with macrophage vacuoles containing the opportunistic pathogen Burkholderia cenocepacia
}

Correspondence
Miguel A. Valvano
mvalvano@uwo.ca

Received 16 December 2008

Revised 16 January 2009

Accepted 20 January 2009

\author{
Karen E. Keith, ${ }^{1}$ Daniel W. Hynes, ${ }^{1}$ Judith E. Sholdice ${ }^{1}$ \\ and Miguel A. Valvano ${ }^{1,2}$ \\ ${ }^{1}$ Infectious Diseases Research Group, Siebens-Drake Research Institute, Department of
Microbiology and Immunology, University of Western Ontario, London, ON N6A 5C1, Canada
${ }^{2}$ Department of Medicine, University of Western Ontario, London, ON N6A 5C1, Canada
}

\begin{abstract}
Burkholderia cenocepacia causes chronic lung infections in patients suffering from cystic fibrosis and chronic granulomatous disease. We have previously shown that $B$. cenocepacia survives intracellularly in macrophages within a membrane vacuole $(\mathrm{BcCV})$ that delays acidification. Here, we report that after macrophage infection with live $B$. cenocepacia there is a $\sim 6 \mathrm{~h}$ delay in the association of $\mathrm{NADPH}$ oxidase with $\mathrm{BcCVs}$, while heat-inactivated bacteria are normally trafficked into NADPH oxidase-positive vacuoles. BcCVs in macrophages treated with a functional inhibitor of the cystic fibrosis transmembrane conductance regulator exhibited a further delay in the assembly of the NADPH oxidase complex at the BcCV membrane, but the inhibitor did not affect NADPH oxidase complex assembly onto vacuoles containing heat-inactivated $B$. cenocepacia or live Escherichia coli. Macrophages produced less superoxide following $B$. cenocepacia infection as compared to heat-inactivated B. cenocepacia and E. coli controls. Reduced superoxide production was associated with delayed deposition of cerium perhydroxide precipitates around $\mathrm{BcCV}$ s of macrophages infected with live $B$. cenocepacia, as visualized by transmission electron microscopy. Together, our results demonstrate that intracellular $B$. cenocepacia resides in macrophage vacuoles displaying an altered recruitment of the NADPH oxidase complex at the phagosomal membrane. This phenomenon may contribute to preventing the efficient clearance of this opportunistic pathogen from the infected airways of susceptible patients.
\end{abstract}

\section{INTRODUCTION}

Phagocyte NADPH oxidase plays a crucial role in host defence by professional phagocytes such as neutrophils and macrophages. The NADPH oxidase consists of two membrane-bound (gp91 ${ }^{\text {phox }}$ and $\mathrm{p} 22^{\text {phox }}$ ) and four cytoplasmic subunits $\left(\mathrm{p} 47^{\text {phox }}, \mathrm{p} 67^{\text {phox }}, \mathrm{p} 40^{\text {phox }}\right.$ and Rac). The enzyme is dormant in resting phagocytes but after activation by soluble stimuli or phagocytosis the complex is assembled and becomes active, generating large quantities of superoxide anions at the plasma or phagosomal membrane (Segal, 2005; Takeya \& Sumimoto, 2003). The resulting superoxide is a precursor of more potent microbicidal reactive oxygen species (ROS) such as hydrogen peroxide, hydroxyl radical

Abbreviations: AT, 3-amino-1,2,4-triazole; Bcc, Burkholderia cepacia complex; BcCV, Burkholderia cenocepacia-containing vacuole; $\mathrm{CF}$, cystic fibrosis; CFTR, cystic fibrosis transmembrane conductance regulator; CGD, chronic granulomatous disease; DMEM, Dulbecco's modified Eagle medium; DPI, diphenyleneiodonium chloride; FBS, fetal bovine serum; mRFP1, monomeric red-fluorescent protein 1; NBT, nitro blue tetrazolium; PMA, phorbol 12-myristate 13-acetate; ROS, reactive oxygen species. and hypochlorous acid (Fang, 2004). Localized production of ROS by the NADPH oxidase complex is spatially regulated and requires the recruitment of the membrane components to the phagosome and the assembly of cytoplasmic regulatory proteins on the phagosomal membrane (Minakami \& Sumimotoa, 2006).

The integral membrane proteins gp $91^{\text {phox }}$ and $\mathrm{p} 22^{\text {phox }}$ form flavocytochrome $b_{558}$, the catalytic centre of the NADPH oxidase (Vignais, 2002). gp91 ${ }^{\text {phox }}$ belongs to the NADPH oxidase (Nox) family and has six transmembrane helices and two haem moieties, enabling this protein to transport an electron across the membrane. This electron is then donated to an oxygen molecule in the vacuolar lumen, producing the superoxide anion. $\mathrm{p} 22^{\text {phox }}$ has two transmembrane helices and a proline-rich region in the Cterminal cytoplasmic tail. p22 $2^{\text {phox }}$ stabilizes gp $91^{\text {phox }}$ at the protein level and acts as an anchor for the soluble regulatory proteins essential for NADPH oxidase function (Minakami \& Sumimotoa, 2006).

The process of NADPH oxidase assembly has been elucidated in neutrophils, but less is known about the 
mechanism of assembly in macrophages. In neutrophils, the disassociation of the cytoplasmic $\mathrm{p} 47^{\text {phox }}, \mathrm{p} 67^{\text {phox }}$ and $\mathrm{p} 40^{\text {phox }}$ ternary complex upon activation results in the phosphorylation and translocation of $\mathrm{p} 47^{\text {phox }}$ to the membrane. $\mathrm{p} 67^{\text {phox }}$ is then recruited via $\mathrm{p} 47^{\text {phox }}$, with Rac translocating independently of $\mathrm{p} 47^{\text {phox }}$ and $\mathrm{p} 67^{\text {phox }}$ (Bokoch \& Diebold, 2002; De Leo et al., 1996; Han et al., 1998; Heyworth et al., 1991). p40 phox facilitates the membrane translocation of both $\mathrm{p} 47^{\text {phox }}$ and $\mathrm{p} 67^{\text {phox }}$ but not Rac (Kuribayashi et al., 2002; Ueyama et al., 2007). The NADPH oxidase only produces superoxide after all subunits are correctly translocated to the membrane.

The vital role of NADPH oxidase in innate immunity is clearly illustrated in chronic granulomatous disease (CGD), a rare genetic disorder caused by mutations in several genes encoding subunits of the NADPH oxidase and a subsequent negligible production of vacuolar ROS (Vignais, 2002). CGD patients suffer from recurrent bacterial and fungal infections, which begin early in life, are difficult to treat, and often prove fatal (Dinauer \& Orkin, 1992). Many pathogens have evolved various strategies for $\mathrm{NADPH}$ oxidase inhibition and avoidance of superoxide-mediated damage. For example, the Salmonella enterica pathogenicity island 2 (SPI-2) encodes type III-secreted effector proteins that when translocated into host cells result in mislocalization of NADPH oxidase (Gallois et al., 2001; Vazquez-Torres et al., 2000; VazquezTorres \& Fang, 2001; Waterman \& Holden, 2003). Anaplasma phagocytophilum uses a different strategy to suppress the respiratory burst in neutrophils by preventing fusion of bacteria-containing vacuoles with secretory vesicles and specific granules trafficking flavocytochrome $b_{558}$ (Mott et al., 2002). A. phagocytophilum can also modify gp91 ${ }^{\text {phox }}$ promoter activity (Carlyon \& Fikrig, 2006). The uptake of Leishmania donovani amastigotes by murine macrophages occurs without the phosphorylation of $47^{\text {phox }}$, abrogating the recruitment of $\mathrm{p} 47^{\text {phox }}$ and p $67^{\text {phox }}$ and superoxide production. The amastigotes also disrupt phagosomal lipid raft integrity, potentially interfering with NADPH oxidase assembly (Lodge \& Descoteaux, 2006; Lodge et al., 2006). Helicobacter pylori also disrupts NADPH oxidase targeting in neutrophils, resulting in the release of superoxide anions into the extracellular milieu, preventing their accumulation in the H. pylori-containing phagosome (Allen et al., 2005). Pigments from a number of $\gamma$-proteobacteria, termed prodigiosins, inhibit the production of superoxide by preventing the assembly of $447^{\text {phox }}$ and Rac with flavocytochrome $b_{558}$ in RAW 264.7 macrophages (Nakashima et al., 2008).

The Burkholderia cepacia complex (Bcc) is a group of closely related bacteria found ubiquitously in the environment (Coenye \& Vandamme, 2003; Mahenthiralingam et al., 2005). Bcc species have emerged as important multidrug-resistant pathogens, particularly in patients suffering from cystic fibrosis (CF) (Isles et al., 1984) and CGD (Bylund et al., 2005; Guide et al., 2003). B. cenocepacia and
B. multivorans account for the majority of infections in $\mathrm{CF}$ patients worldwide (Lipuma, 2005; Mahenthiralingam et al., 2008). Bcc species can survive in amoebae (Lamothe et al., 2004; Landers et al., 2000; Marolda et al., 1999), human respiratory epithelial cells (Burns et al., 1996; Keig et al., 2002; Sajjan et al., 2006) and macrophages (Lamothe et al., 2007; Martin \& Mohr, 2000; Sajjan et al., 2008). B. cenocepacia can also delay the maturation of the phagosome, which may facilitate evasion of host cell microbicidal activities (Lamothe et al., 2007).

Evidence suggests that Bcc strains can overcome oxidative damage by macrophages and neutrophils. In previous studies, we demonstrated that intracellular survival in macrophages infected with Bcc isolates occurs despite an oxidative burst (Saini et al., 1999), and requires production of a periplasmic superoxide dismutase (Keith \& Valvano, 2007) and a melanin-like pigment (Keith et al., 2007). Others have shown that the exopolysaccharide capsule material produced by mucoid strains of $B$. cenocepacia can interfere with the function of human neutrophils in vitro by inhibiting chemotaxis and ROS (Bylund et al., 2005). However, whether intracellular Bcc bacteria affect the formation of an active NADPH complex has not been directly investigated. Since intracellular B. cenocepacia can actively modulate the maturation of the $\mathrm{BcCV}$ by delaying acidification and recruitment of late endosomal and lysosomal markers (Lamothe et al., 2007) it is conceivable that the formation of an active NADPH complex may also be altered. In this work, we demonstrate that BcCVs exhibit a delayed association with an NADPH oxidase-positive vacuole, and this delay is further exaggerated in macrophages treated with a specific inhibitor of the cystic fibrosis transmembrane conductance regulator (CFTR). Visualization of superoxide-induced electron-dense deposits in situ by transmission electron microscopy demonstrated delayed superoxide formation around BcCVs. Together these data reveal that intracellular B. cenocepacia interferes with the formation of an active NADPH oxidase complex in macrophages.

\section{METHODS}

Reagents and antibodies. Dulbecco's modified Eagle medium (DMEM), RPMI 1640, PBS and fetal bovine serum (FBS) were obtained from Wisent. Polyclonal primary antibodies [goat antimouse $\mathrm{p} 40^{\text {phox }}(\mathrm{N}-20)$ antibody and rabbit anti-mouse $\mathrm{p} 22^{\text {phox }}$ (FL195)] were purchased from Santa Cruz Biotechnology. The secondary AlexaFluor 488-conjugated chicken anti-goat and AlexaFluor 647-conjugated goat anti-rabbit antibodies were purchased from Invitrogen. Cerium chloride, phorbol 12-myristate 13acetate (PMA) and CFTR $_{\text {inh }}-172$ were purchased from Sigma Aldrich. $\mathrm{CFTR}_{\text {inh-172 }}$ was used at a final concentration of $10 \mu \mathrm{M}$.

Bacterial strains, macrophages and culture conditions. $B$. cenocepacia strain J2315 was chosen as a representative strain of the highly transmissible ET-12 clone (Mahenthiralingam et al., 2000). Escherichia coli $\mathrm{DH} 5 \alpha\left[\mathrm{F}^{-} \phi 80\right.$ lacZ $\Delta \mathrm{M} 15$ endA recA hsdR $\left(\mathrm{r}_{\mathrm{K}}^{-} \mathrm{m}_{\mathrm{K}}^{-}\right)$supE thi gyrA relA $\triangle($ lacZYA-argF) U169] was from our laboratory stocks. Bacteria were grown in Luria-Bertani (LB) broth at $37^{\circ} \mathrm{C}$ with 
shaking. B. cenocepacia carrying the plasmid pJRL1, which expresses the monomeric red-fluorescent protein 1 (mRFP1) (Lamothe et al., 2007), was grown in the presence of $100 \mu \mathrm{g}$ trimethoprim $\mathrm{ml}^{-1}$. E. coli $\mathrm{DH} 5 \alpha$ carrying the plasmid pRedCm4 was grown with $30 \mu \mathrm{g}$ chloramphenicol $\mathrm{ml}^{-1}$. This plasmid is a derivative of pME6000 (Lefebre \& Valvano, 2002) that contains the gene encoding mRFP1 and also confers chloramphenicol resistance. The murine macrophage-like cell line RAW 264.7 (TIB-71, ATTC, Manassas, VA, USA) was maintained in DMEM with $10 \%$ fetal bovine serum and grown at $37{ }^{\circ} \mathrm{C}$ in a humidified atmosphere of $5 \% \mathrm{CO}_{2}$.

Macrophage infection assays. Bacteria were washed twice with HEPES-buffered RPMI 1640 and suspended in DMEM plus $10 \%$ fetal bovine serum. For heat inactivation, bacteria were incubated at $60{ }^{\circ} \mathrm{C}$ for 25 min prior to infection. We have previously determined that non-opsonic phagocytosis of J2315 by RAW 264.7 macrophages at an m.o.i. of 30-50 results in a reasonable proportion of infected macrophages with a sufficient number of intracellular bacteria for microscopic analysis (Lamothe et al., 2007). Therefore, macrophages were seeded onto glass (or plastic for transmission electron microscopy; see below) coverslips in six-well tissue culture plates and bacteria were added at an m.o.i. of 30 , centrifuged at $300 \mathrm{~g}$ and incubated at $37{ }^{\circ} \mathrm{C}$ under $5 \% \mathrm{CO}_{2}$ for the desired time of infection. Infected macrophages were washed three times with HEPES-buffered RPMI 1640 before fixing and immunostaining.

Immunostaining and confocal microscopy. Cells were fixed with $4 \%(\mathrm{v} / \mathrm{v})$ paraformaldehyde for $30 \mathrm{~min}$ at room temperature and incubated with $100 \mathrm{mM}$ glycine in PBS $(1 \times)$. Cells were then permeabilized with $0.1 \%(\mathrm{v} / \mathrm{v})$ Triton X-100 and blocked with $5 \%$ $(\mathrm{w} / \mathrm{v})$ milk powder for $1 \mathrm{~h}$ at room temperature. Permeabilized cells were incubated with primary antibodies, followed by secondary antibodies in $5 \%(\mathrm{w} / \mathrm{v})$ milk for $1 \mathrm{~h}$ each at room temperature. Coverslips were mounted on glass slides using fluorescent mounting medium (Dako). Primary antibodies were used at $1: 50$ dilution and secondary antibodies were used at 1:1000 dilution. Confocal microscopy was performed using a Zeiss LSM 510 laser scanning confocal microscope with an oil-immersion $\times 100$ objective. For triple-fluorescence experiments bacterial cells expressing mRFP1 were pseudocoloured in blue.

Cerium perhydroxide localization by transmission electron microscopy. RAW 264.7 macrophages were seeded onto either glass or Thermanox plastic coverslips in six-well tissue culture plates and bacteria were added at an m.o.i. of 30 , centrifuged at $300 \mathrm{~g}$, and incubated at $37{ }^{\circ} \mathrm{C}$ under $5 \% \mathrm{CO}_{2}$ for the desired time of infection. Cells were washed briefly at $4{ }^{\circ} \mathrm{C}$ in $0.1 \mathrm{M}$ Tris/maleate buffer, $\mathrm{pH} 7.5,7 \%$ sucrose and pre-incubated with the same buffer containing $1 \mathrm{mM} \mathrm{3}$-amino-1,2,4-triazole (AT) at $37{ }^{\circ} \mathrm{C}$ for $10 \mathrm{~min}$, and then $10 \mathrm{mM} \mathrm{AT}, 1 \mathrm{mM} \mathrm{CeCl}_{3}$ and $0.71 \mathrm{mM} \mathrm{NADH}$ at $37^{\circ} \mathrm{C}$ for $20 \mathrm{~min}$. Cerium-containing solutions were filter-sterilized prior to use to remove any cerium hydroxide precipitate arising from spontaneous oxidation.

Prior to processing for transmission electron microscopy, macrophages were washed briefly in $0.1 \mathrm{M}$ Tris/maleate buffer, $\mathrm{pH} 7.5,7 \%$ sucrose at $4{ }^{\circ} \mathrm{C}$ and fixed directly on the coverslips using $2.5 \%$ glutaraldehyde in $0.1 \mathrm{M}$ sodium cacodylate buffer, $\mathrm{pH} 7.3$, containing $5 \%$ sucrose, at $4{ }^{\circ} \mathrm{C}$ for $1 \mathrm{~h}$. Coverslips were washed in $0.1 \mathrm{M}$ sodium cacodylate buffer, $\mathrm{pH} 6.0 / 5 \%$ sucrose for $1 \mathrm{~h}$ at $4{ }^{\circ} \mathrm{C}$, and overnight in $0.1 \mathrm{M}$ sodium cacodylate buffer, $\mathrm{pH} 7.3 / 5 \%$ sucrose. Macrophages were post-fixed in $1 \%$ osmium tetroxide in $0.1 \mathrm{M}$ sodium cacodylate buffer, $\mathrm{pH} 7.3$, for $1 \mathrm{~h}$, and coverslips were washed with $0.1 \mathrm{M}$ sodium cacodylate buffer, $\mathrm{pH}$ 7.3. This was followed by dehydration through graded alcohols, infiltration overnight in a 50:50 mixture of absolute ethanol/Epon 812 resin, and infiltration in $100 \%$ Epon 812 resin for $2.5 \mathrm{~h}$. Samples were then embedded for sectioning in the plane of the monolayer, and sections were stained with $2 \%$ uranyl acetate and lead citrate and visualized using a Philips 410 transmission electron microscope operating at $60 \mathrm{kV}$.

Quantification of intracellular superoxide. Intracellular superoxide formation was measured by determining spectrophotometrically the reduction of nitro blue tetrazolium (NBT), which results in insoluble blue deposits inside macrophages (Rook et al., 1985). RAW 264.7 macrophages $\left(2.5 \times 10^{5}\right.$ per well $)$ were seeded into 24 -well plates and incubated for $16 \mathrm{~h}$ in DMEM $+10 \%$ FBS. The medium was aspirated and the cells washed twice with RPMI. NBT at a concentration of $1.25 \mathrm{mg} \mathrm{ml}^{-1}$ was freshly prepared and pre-warmed to $37{ }^{\circ} \mathrm{C}$ prior to use. From this solution, $300 \mu \mathrm{l}$ was added to each well, bacteria were added at an m.o.i. of 30 in DMEM $+10 \%$ FBS, and the final volume was brought to $1 \mathrm{ml}$ with DMEM $+10 \%$ FBS. As a positive control, $2 \mu \mathrm{g}$ PMA ml ${ }^{-1}$ per well was added to uninfected macrophages. Infections were allowed to proceed for the desired time, at which point the supernatant was aspirated and the cells were washed twice with $1 \mathrm{ml}$ RPMI, followed by two washes with $1 \mathrm{ml}$ methanol. The wells were then air-dried and the reduced NBT deposits solubilized by adding $240 \mu \mathrm{l} 2 \mathrm{M} \mathrm{KOH}$ per well followed by $280 \mu \mathrm{l}$ DMSO per well. The $A_{570}$ of the resulting blue solution was determined using a spectrophotometer. Background values were determined by incubation of uninfected RAW 264.7 cells. A standard curve was established by measuring the $A_{570}$ of serial dilutions of a $1 \mathrm{mg}$ NBT $\mathrm{ml}^{-1}$ solution (in 1.2:1.4 $2 \mathrm{M} \mathrm{KOH} / \mathrm{DMSO}$ ). The NADPH oxidase inhibitor diphenyleneiodonium chloride (DPI) (O’Donnell et al., 1993) was used to determine that NBT reduction was due strictly to the metabolic products of the respiratory burst of the macrophages. All samples were repeated with DPI added to a final concentration of $10 \mu \mathrm{M}$ at the time of infection; these values were then subtracted from the corresponding well minus the DPI, giving the amount of NADPH oxidase-dependent NBT reduction.

Statistical analyses. Statistical analyses were done using GraphPad Prism version 4.03 (GraphPad Software) by two-way ANOVA and Students' $t$-test, as appropriate.

\section{RESULTS}

\section{RAW 264.7 macrophages express the p22 ${ }^{\text {phox }}$ and p40 ${ }^{\text {phox }}$ subunits of the NADPH oxidase and become activated by exposure to PMA}

We initially evaluated the subcellular localization of the membrane-bound $\mathrm{p} 22^{\text {phox }}$ and cytoplasmic $40^{\text {phox }}$ NADPH oxidase subunits in resting RAW 264.7 macrophages by confocal fluorescence microscopy. Analysis of the distribution of these proteins in macrophage cells demonstrated that $\mathrm{p} 40^{\text {phox }}$ was diffusely localized throughout the cytoplasm while $\mathrm{p} 22^{\text {phox }}$ exhibited punctate staining in the cytoplasm and also localization on the plasma membrane (Fig. 1a). Only sporadically, the subunits showed partial colocalization as shown in the merged images (Fig. 1a, arrows), but for the most part they were clearly found spatially segregated within the cell. Stimulation of the macrophages with PMA results in the activation of protein kinase $\mathrm{C}$, which in turn phosphorylates the cytoplasmic $47^{\text {phox }}$ subunit of the NADPH oxidase complex, causing the complex to assemble and generate superoxide (Nauseef et al., 1991). Stimulation of RAW 264.7 macrophages with $2 \mu \mathrm{g}$ PMA ml ${ }^{-1}$ over a 


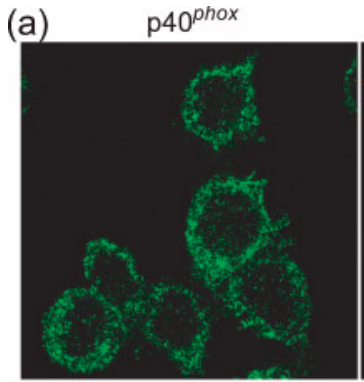

(b) $\quad \mathrm{p} 40^{\text {phox }}$

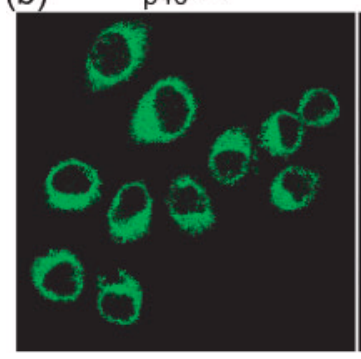

p22 $2^{\text {phox }}$

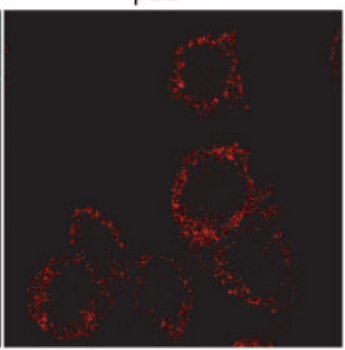

$\mathrm{p} 22^{\text {phox }}$

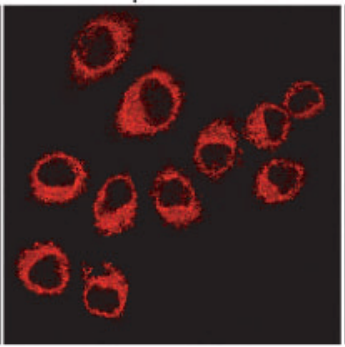

merge

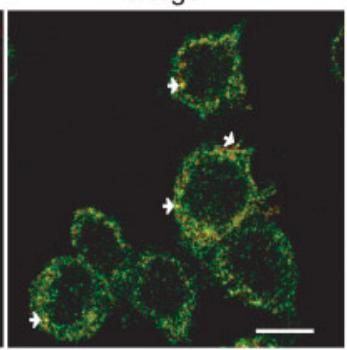

merge

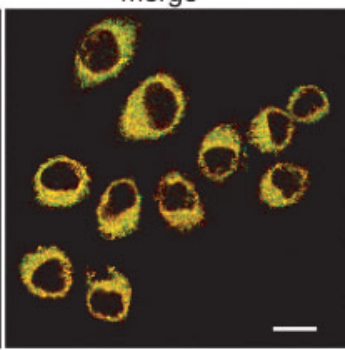

Fig. 1. Distribution of $\mathrm{p} 22^{\text {phox }}$ and $\mathrm{p} 40^{\text {phox }}$ NADPH oxidase subunits in RAW 264.7 macrophages. (a) p22 phox and $\mathrm{p} 40^{\text {phox }}$ distribution in resting macrophages. (b) $\mathrm{p} 22^{\text {phox }}$ and $\mathrm{p} 40^{\text {phox }}$ distribution in macrophages after stimulation with $2 \mu \mathrm{g} \mathrm{PMA} \mathrm{ml}{ }^{-1}$ for $15 \mathrm{~min}$. Immunolabelling was performed using goat anti-p40 ${ }^{\text {phox }}$ and rabbit anti-p22 $2^{\text {phox }}$ primary antibodies. Chicken antigoat conjugated to AlexaFluor 488 (green fluorescence) and goat anti-rabbit conjugated to AlexaFluor 647 (far red fluorescence) secondary antibodies. Images were captured with an LSM 510 Meta/ConfoCor2 confocal microscope and a $\times 100$ objective. Arrows indicate regions of colocalization in resting macrophages. Bars, $10 \mu \mathrm{m}$. time-course from 0 to $60 \mathrm{~min}$ demonstrated that at $15 \mathrm{~min}$ virtually $100 \%$ of the macrophage cell population exhibited a complete colocalization of $\mathrm{p} 22^{\text {phox }}$ and $\mathrm{p} 40^{\text {phox }}$ subunits (Fig. 1b). Therefore, these experiments demonstrate that colocalization of $\mathrm{p} 22^{\text {phox }}$ and $\mathrm{p} 40^{\text {phox }}$ can be used as a readout for the assembly of the NADPH complex, and reveal that the NADPH oxidase in RAW 264.7 macrophages can rapidly assemble upon PMA stimulation.

\section{BcCVs of macrophages infected with viable $B$. cenocepacia delay the assembly of the NADPH oxidase on the phagosomal membrane}

RAW 264.7 macrophages were infected at an m.o.i. of 30 with B. cenocepacia strain J2315 carrying pJRL1, which constitutively expresses the monomeric red-fluorescent protein mRFP1. At 2, 4 and $6 \mathrm{~h}$ post-infection, macrophages were rinsed numerous times with prewarmed PBS to remove extracellular bacteria, fixed, and immunostained using anti-p22 phox and anti-p40 ${ }^{\text {phox }}$ antibodies. Extensive rinsing with PBS was preferred over antibiotic treatment since in our experience it is difficult to rely on antibiotics for the removal of extracellular B. cenocepacia (Lamothe et al., 2004, 2007; Lamothe \& Valvano, 2008; Marolda et al., 1999; Saini et al., 1999), and this method eliminated the majority of extracellular bacteria as visualized microscopically (data not shown). The distribution of $\mathrm{p} 22^{\text {phox }}$ and $\mathrm{p} 40^{\text {phox }}$ subunits over the time-course of infection was expressed as a percentage of the total number of phagosomes that stained positively for $\mathrm{p} 22^{\text {phox }}$ and $\mathrm{p} 40^{\text {phox }}$ subunits (mean \pm SD of four separate experiments). At $2 \mathrm{~h}$ post-infection, B. cenocepacia J2315 was present in BcCVs, and although both $\mathrm{p} 22^{\text {phox }}$ and $\mathrm{p} 40^{\text {phox }}$ were recruited to the general area of the BcCVs, no BcCVs had a characteristic ring of colocalization of either subunit (Fig. $2 \mathrm{a})$. At $4 \mathrm{~h}$ post-infection, $24 \pm 7 \%$ of $\mathrm{BcCVs}$ exhibited a distinct staining pattern, with both $\mathrm{p} 22^{\text {phox }}$ and $\mathrm{p} 40^{\text {phox }}$ colocalizing on the membrane of the $\mathrm{BcCV}$, forming a ring (Fig. 2b). By $6 \mathrm{~h}$ post-infection both $\mathrm{p} 22^{\text {phox }}$ and $\mathrm{p} 40^{\text {phox }}$ subunits were colocalized on the membrane of the majority of BcCVs, as evidenced by rings surrounding internalized bacteria in $82 \pm 9 \%$ of BcCVs (Fig. 2c). These results suggest that infection of RAW 264.7 macrophages with viable B. cenocepacia J2315 leads to a delayed assembly of the NADPH oxidase complex.

The distribution of $\mathrm{p} 22^{\text {phox }}$ and $\mathrm{p} 40^{\text {phox }}$ was also analysed upon infection of RAW 264.7 macrophages with heatinactivated $B$. cenocepacia. These experiments were done at $2 \mathrm{~h}$ post-infection since at later time points the intracellular bacteria were completely destroyed. BcCVs containing heat-inactivated $B$. cenocepacia were positive for $\mathrm{p} 22^{\text {phox }}$ and $\mathrm{p} 40^{\text {phox }}$, with both subunits forming complete rings of colocalization around the phagosomes (Fig. 2d). To confirm that the delay in NADPH oxidase assembly was specifically dependent on live B. cenocepacia, RAW 264.7 macrophages were infected with $E$. coli DH $5 \alpha(\mathrm{pRedCm} 4)$, which constitutively expresses mRFP1. At $1 \mathrm{~h}$ postinfection, the $\mathrm{p} 22^{\text {phox }}$ and $\mathrm{p} 40^{\text {phox }}$ colocalized to virtually all phagosomes containing E. coli (Fig. 2e). Also, like heatinactivated B. cenocepacia, E. coli cells displayed morphologies suggesting a compromised membrane, including the release of cytoplasmic mRFP1 into the vacuolar lumen, and at later time points, bacteria were destroyed by the macrophages (data not shown). Together, these results suggest that live $B$. cenocepacia is required for the delayed assembly or recruitment of the NADPH phagocyte oxidase on the $\mathrm{BcCV}$ membrane.

The absence of intracellular $B$. cenocepacia replication compounded with the failure to kill extracellular bacteria because of their extraordinary resistance to cell-membraneimpermeable antibiotics prevents us from obtaining viable 

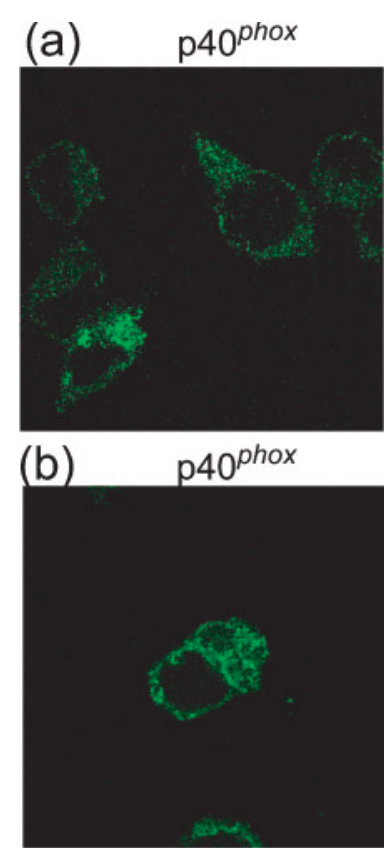

(c)

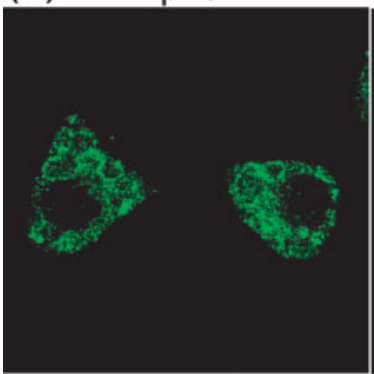

(d) $\quad \mathrm{p} 40^{\text {phox }}$

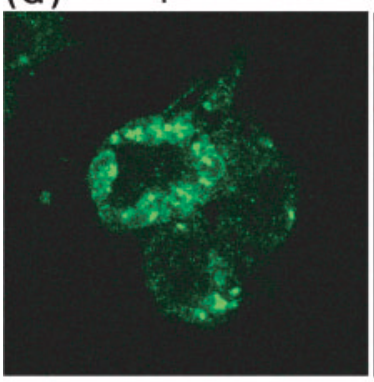

(e)

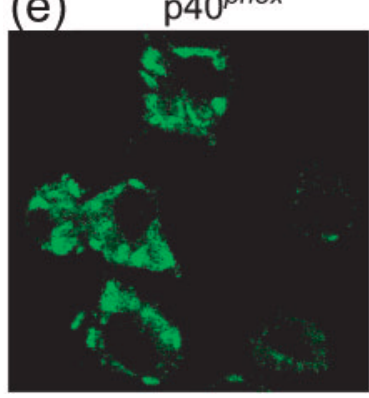

$\mathrm{p} 22^{\text {phox }}$

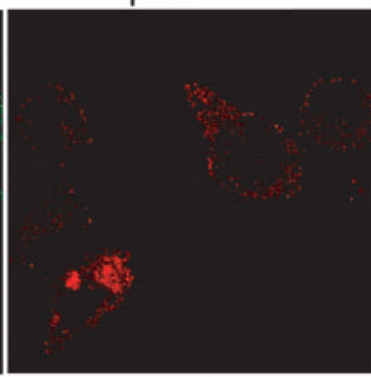

p22 $2^{\text {phox }}$

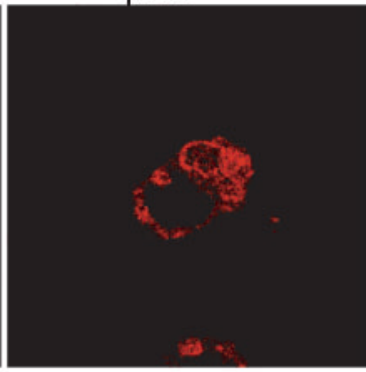

$\mathrm{p} 22^{\text {phox }}$
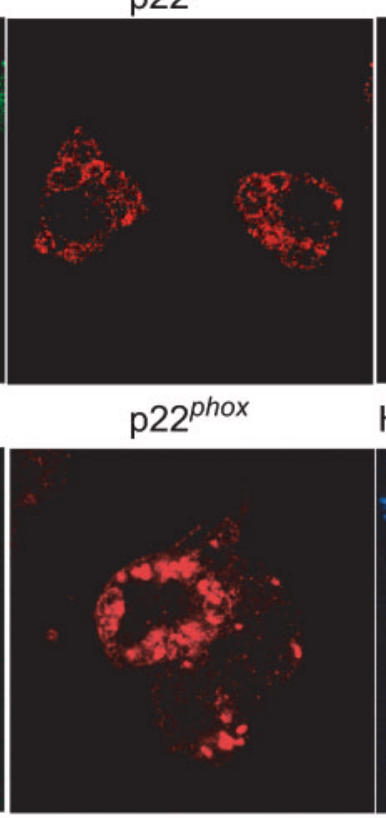

p22 $2^{\text {phox }}$

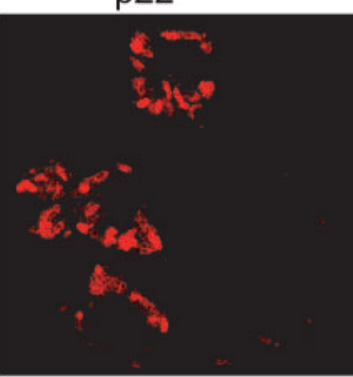

Live J2315

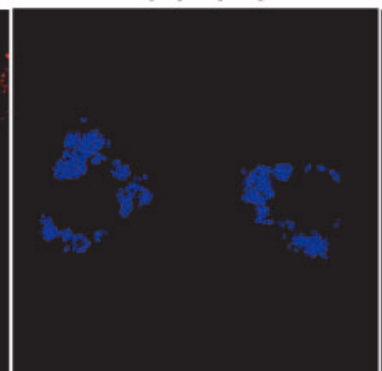

Heat-inactivated J2315

merge

Live J2315

merge

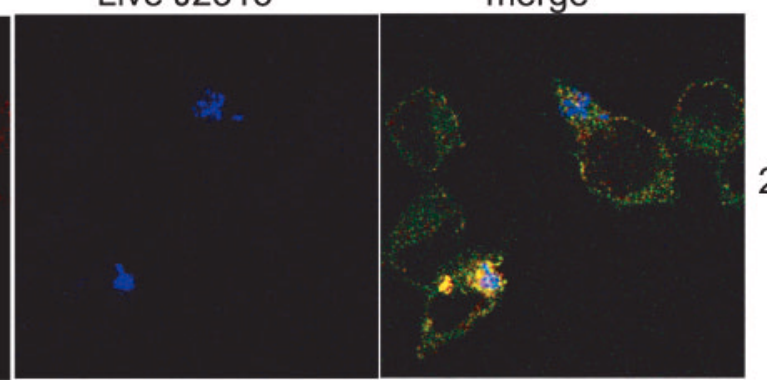

$2 \mathrm{~h}$

$4 \mathrm{~h}$

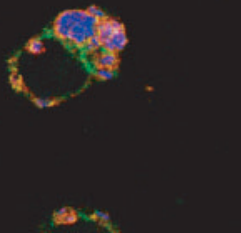

merge

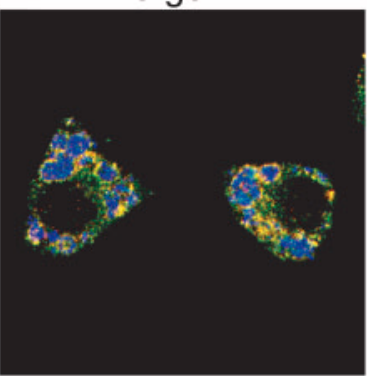

$6 h$

$2 \mathrm{~h}$

$1 \mathrm{~h}$

Fig. 2. Distribution of $p 22^{\text {phox }}$ and $p 40^{\text {phox }} \mathrm{NADPH}$ oxidase subunits in infected RAW 264.7 macrophages at various time points. (a, b, c) Macrophages infected with viable B. cenocepacia J2315(pJRL1) were examined at 2 h (a), 4 h (b) and 6 h (c) post-infection. (d) Macrophages infected with heat-inactivated B. cenocepacia J2315 at 2 h post-infection. (e) Macrophages infected with viable $E$. coli $\mathrm{DH} 5 \alpha(\mathrm{pRedCm} 4)$ at $1 \mathrm{~h}$ post-infection. Immunolabelling and image capture were performed as described in Fig. 1. Bacterial cells were pseudocoloured in blue. Bars, $10 \mu \mathrm{m}$. 
counts in macrophage infection experiments (Lamothe et al., 2007; Saini et al., 1999). However, we can conclude that intracellular $B$. cenocepacia remained viable during the course of the infection as demonstrated by the retention of mRFP1 within the bacterial cytoplasm. We have previously demonstrated that intracellular $B$. cenocepacia reaching the lysosomes rapidly lose cell envelope integrity, resulting in the dispersal of the fluorescent protein throughout the phagosomal lumen, which serves as an indication of bacterial cell disruption (Lamothe et al., 2007). This is particularly obvious with heat-killed bacteria, which retain the fluorescence if they are kept in buffer but leak fluorescence into the phagosomal lumen after phagocytosis (Lamothe et al., 2004, 2007). Therefore, retention of mRFP1 within the bacterial cytoplasm in more than $80 \%$ of the vacuoles after infection with live B. cenocepacia (data not shown) provides good evidence that the bacterial cell envelope remains intact, and is consistent with previous observations in other studies (Lamothe et al., 2007; Maloney \& Valvano, 2006; Saldías et al., 2008).

\section{Inhibition of CFTR function increases the delay in NADPH oxidase assembly}

CF patients carry mutations in a gene encoding a cAMPregulated chloride channel called the CFTR (Cheng et al., 1990). We have recently observed that after infection with B. cenocepacia, the BcCVs in CFTR-defective macrophages or macrophages pre-treated with a CFTR functional inhibitor exhibit a more extended delay in acidification and phagolysosomal fusion than that usually observed in wild-type macrophages (Lamothe \& Valvano, 2008). The CFTR-associated phagosomal maturation defect is only detected upon infection of macrophages with live $B$. cenocepacia, and is absent in macrophages exposed to heat-inactivated bacteria or macrophages infected with a non-CF pathogen such as Salmonella enterica (Lamothe \& Valvano, 2008). To examine whether the absence of CFTR function has any effect on the assembly of the NADPH oxidase complex upon infection with B. cenocepacia, RAW 264.7 macrophages were incubated for $30 \mathrm{~min}$ prior to infection with the CFTR functional inhibitor molecule $\mathrm{CFTR}_{\mathrm{inh}}-172$ (Ma et al., 2002). The distribution of $\mathrm{p} 22^{\text {phox }}$ and $\mathrm{p} 40^{\text {phox }}$ was assessed by immunostaining and confocal microscopy as described above. At $2 \mathrm{~h}$ post-infection p $22^{\text {phox }}$ and $440^{\text {phox }}$ were spatially segregated in the macrophage, with a distribution similar to that observed for resting macrophages in Fig. 1(a) (data not shown), while at $4 \mathrm{~h}$ post-infection there was partial colocalization of the p $22^{\text {phox }}$ and $\mathrm{p} 40^{\text {phox }}$ subunits (Fig. 3a). These areas of colocalization were in the vicinity of the BcCVs and did not form distinctive rings on the $\mathrm{BcCV}$ membrane as described at the $4 \mathrm{~h}$ time point in the absence of the CFTR inhibitor (Fig. 2b). At 6 h post-infection both p $22^{\text {phox }}$ and $\mathrm{p} 40^{\text {phox }}$ were found to colocalize, particularly on the plasma membrane of the macrophage, but not specifically on the membrane of the BcCV (Fig. 3b). Some colocalization of the subunits was observed in the vicinity of the $\mathrm{BcCVs}$, but the distinctive rings of colocalization that were observed on the membrane of the $\mathrm{BcCV}$ at $6 \mathrm{~h}$ post-infection with no inhibitor (Fig. 2c) were seen in only a small percentage of BcCVs. The kinetics of the association of $\mathrm{BcCVs}$ with p22 phox and $\mathrm{p} 40^{\text {phox }}$ rings were assessed over time, with at least $150 \mathrm{BcCVs}$ counted from 21 different fields of view per time point (Fig. 4). At $2 \mathrm{~h}$ post-infection, with and without the CFTR inhibitor, no rings of NADPH oxidase colocalization were observed on the $\mathrm{BcCV}$ membrane. At $4 \mathrm{~h}$ post-infection, rings of colocalization were observed in $23 \pm 6 \%$ of $\mathrm{BcCVs}$; this number was reduced almost 16fold to $1.5 \pm 0.7 \%$ when macrophages were pre-incubated with the CFTR inhibitor. At $6 \mathrm{~h}$ post-infection, rings of colocalization were observed in $82 \pm 9 \%$ of $\mathrm{BcCVs}$, but this number was reduced almost 8 -fold to $10 \pm 8 \%$ when macrophages were pre-incubated with the CFTR inhibitor. Since CFTR inh $^{-172}$ specifically reduces CFTR function (Ma et al., 2002), these results suggest that the loss of CFTR function in RAW 264.7 macrophages further increases the delay in assembly of the NADPH oxidase complex on the plasma membrane of the $\mathrm{BcCV}$. To investigate if this delay was specific to the inhibition of CFTR, or due to CFTR inhibition in combination with $B$. cenocepacia infection, these experiments were repeated with $E$. coli and heatinactivated B. cenocepacia. At $2 \mathrm{~h}$ post-infection with heatinactivated $B$. cenocepacia the addition of the CFTR inhibitor did not delay the assembly of the NADPH oxidase on the $\mathrm{BcCV}$ membrane, and complete rings of colocalization were observed (data not shown). Preincubation with the CFTR inhibitor followed by a $1 \mathrm{~h}$ infection with E. coli did not delay the assembly of the NADPH oxidase on the phagosomal membrane (Fig. 3c). Also, treatment with the $\mathrm{CFTR}_{\text {inh }^{-172}}$ inhibitor did not prevent degradation of E. coli within the phagosome, as previously observed for the infection in the absence of inhibitor. We conclude from these results that the delayed NADPH oxidase assembly phenotype observed upon infection with live $B$. cenocepacia is enhanced in the presence of the CFTR functional inhibitor.

\section{Intracellular superoxide production during B. cenocepacia infection of RAW 264.7 macrophages and visualization of NADPH oxidase activity in relation to the $\mathrm{BCCV}$}

To determine the effect of $B$. cenocepacia infection on the formation of superoxide by macrophages, we measured superoxide release using the NADPH-dependent reduction of NBT. Macrophages were subjected to a time-course of $B$. cenocepacia infection and the amount of DPI-inhibitable NBT reduction was measured as described in Methods. Using DPI, an inhibitor of the NADPH oxidase, allowed us to determine NBT reduction levels caused strictly by the metabolic products of the macrophages' respiratory burst. At $2 \mathrm{~h}$ post-infection $18 \pm 4 \mu \mathrm{g}$ DPI-inhibitable NBT reduction $\mathrm{ml}^{-1}$ was observed; this increased to $38 \pm 1 \mu \mathrm{g}$ $\mathrm{ml}^{-1}$ at $4 \mathrm{~h}$ and to $56 \pm 3 \mu \mathrm{g} \mathrm{ml}^{-1}$ at $6 \mathrm{~h}$. Infection for $2 \mathrm{~h}$ with live or heat-inactivated $E$. coli resulted in $30 \pm 4 \mu \mathrm{g}$ 


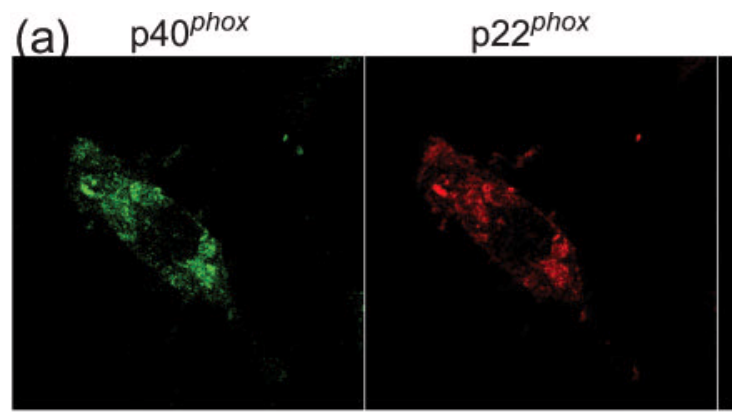

Live J2315

merge
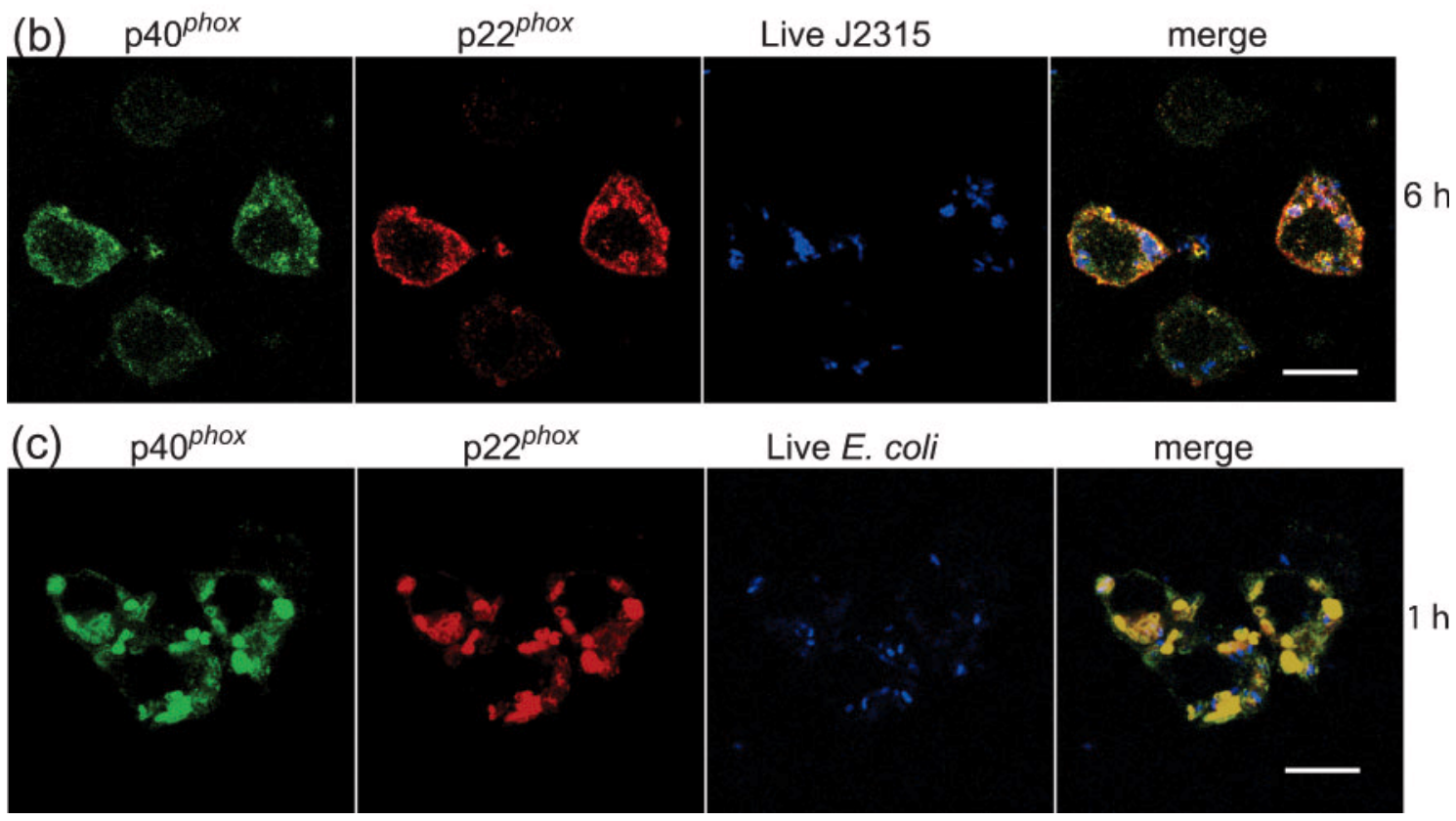

Fig. 3. Effect of CFTR inhibition on the distribution of $\mathrm{p} 22^{\text {phox }}$ and $\mathrm{p} 40^{\text {phox }}$ NADPH oxidase subunits in RAW 264.7 macrophages treated with CFTR inh $^{-172}$. (a) Distribution at $4 \mathrm{~h}$ post-infection with B. cenocepacia J2315. (b) Distribution at $6 \mathrm{~h}$ post-infection with $B$. cenocepacia J2315. (c) Distribution at $1 \mathrm{~h}$ post-infection with $E$. coli DH5 $\alpha$. Immunolabelling and image capture were performed as described in Fig. 1. Bacterial cells were pseudocoloured in blue. Bars, $10 \mu \mathrm{m}$.

$\mathrm{ml}^{-1}$ and $55 \pm 7 \mu \mathrm{g} \mathrm{ml} \mathrm{m}^{-1}$ of DPI-inhibitable NBT reduction, respectively. Infection with heat-inactivated $B$. cenocepacia for $2 \mathrm{~h}$ resulted in $25 \pm 3 \mu \mathrm{g} \mathrm{ml} \mathrm{ml}^{-1}$ of DPIinhibitable NBT reduction. These results demonstrate that the amount of superoxide produced by RAW 264.7 macrophages infected with live $B$. cenocepacia is reduced at similar time points when compared to E. coli and heatinactivated controls (Fig. 5).

To determine the in situ formation of superoxide in the vicinity of the $\mathrm{BcCVs}$, ultrastructural studies were performed on infected RAW 264.7 macrophages that were treated with cerium chloride (Fig. 6). Upon exposure to hydrogen peroxide, cerium chloride is converted to an electron-dense cerium perhydroxide precipitate (Telek et al., 1999). Transmission electron microscopy revealed that at $2 \mathrm{~h}$ post-infection BcCVs did not show detectable deposits of cerium perhydroxide (Fig. 6b, c). Small deposits of cerium perhydroxide were present on the plasma membrane of the macrophage (Fig. 6a). At $4 \mathrm{~h}$ postinfection, electron-dense precipitates were observed on the membrane of some BcCVs, forming punctate patterns, but only a minority of $\mathrm{BcCVs}$ had complete rings of precipitate on the membrane (Fig. 6d) and some BcCVs had no precipitate at all (Fig. 6e, f). In contrast, at $6 \mathrm{~h}$ postinfection most BcCVs had rings of precipitate on their membranes (Fig. $6 \mathrm{~g}-\mathrm{i}$ ). These results confirm that the $\mathrm{NADPH}$ oxidase is assembled on the membrane of BcCVs and is active by $6 \mathrm{~h}$ post-infection. As controls, macrophages infected with $E$. coli and heat-inactivated $B$. cenocepacia were also examined by transmission electron microscopy. Rings of precipitate were seen on the membranes of vacuoles containing E. coli (Fig. 6j, k) and heat-inactivated B. cenocepacia (Fig. 6l) at $1 \mathrm{~h}$ and $2 \mathrm{~h}$ post-infection, respectively. Therefore, the histochemical localization of superoxide production parallels the observed colocalization kinetics for $\mathrm{p} 22^{\text {phox }}$ and $\mathrm{p} 40^{\text {phox }}$ NADPH oxidase subunits, supporting the notion that 


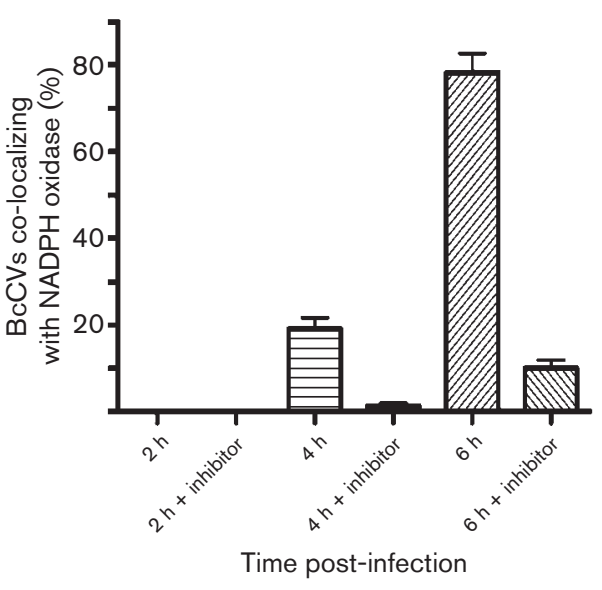

Fig. 4. Kinetics of association of $\mathrm{BcCVs}$ with $\mathrm{p} 22^{\text {phox }}$ and $\mathrm{p} 40^{\text {phox }}$ NADPH oxidase subunits with and without pre-incubation with $\mathrm{CFTR}_{\text {inh }}-172$. Values represent the mean \pm SD of three independent experiments in which at least $150 \mathrm{BcCVs}$ from 21 fields of view were examined at $\times 100$.

BcCVs arising from infection of macrophages with viable B. cenocepacia delay the assembly of a functional NADPH oxidase complex.

\section{DISCUSSION}

Chronic lung infection progressively compromises lung function in CF patients, ultimately leading to the death of the patient. Macrophages play a central role in immunological homeostasis and host defence of the respiratory

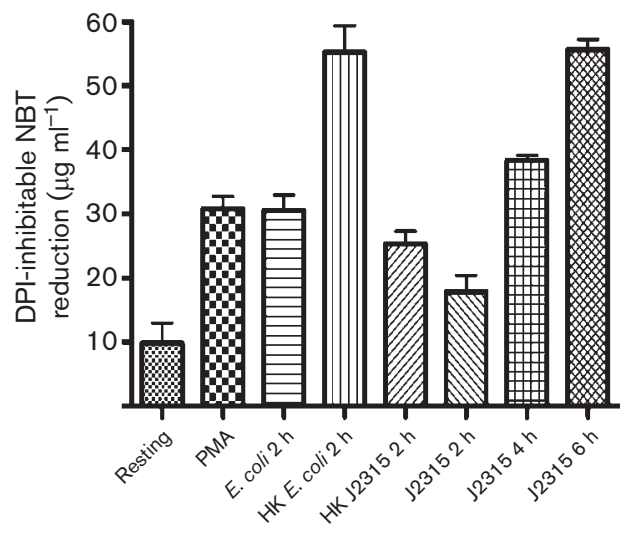

Fig. 5. Quantification of intracellular superoxide production in RAW 264.7 macrophages based on DPI-inhibitable NBT reduction as described in Methods. Macrophages were treated with PMA for $15 \mathrm{~min}$, or exposed to $E$. coli, viable $B$. cenocepacia J2315 or heat-inactivated (HK) B. cenocepacia J2315 for the indicated times. Values represent the mean $\pm \mathrm{SD}$ of three independent experiments. tract (Holt et al., 2008). The virulence factors responsible for the persistence of B. cenocepacia and other Bcc bacteria, as well as the specific bacterial properties associated with tropism for the airways of CF and other immunocompromised patients, are still not fully understood. Intracellular survival of Bcc bacteria within macrophages and epithelial cells may contribute to bacterial persistence within the lung and airways of CF patients, and sustained tissue inflammation and subsequent tissue destruction (Chiu et al., 2001; Valvano et al., 2005; Valvano, 2006).

In this study, we demonstrate that B. cenocepacia is initially internalized into a $\mathrm{BcCV}$ that does not colocalize with either $\mathrm{p} 22^{\text {phox }}$ or $\mathrm{p} 40^{\text {phox }}$ for at least $2 \mathrm{~h}$ post-infection, followed by a progressive increase in the association of both NADPH oxidase subunits until $\sim 6 \mathrm{~h}$, when association reaches more than $80 \%$. This delay in assembly of $\mathrm{NADPH}$ oxidase subunits on the membrane of the phagosome was specific to live B. cenocepacia, as both heat-inactivated B. cenocepacia and live E. coli are present in a phagosome that completely colocalizes with $\mathrm{p} 22^{\text {phox }}$ and $440^{\text {phox }}$ NADPH oxidase subunits at 2 and $1 \mathrm{~h}$ postinfection, respectively. The confocal microscopy experiments did not provide information about the activity of the $\mathrm{NADPH}$ oxidase once it was assembled on the BcCV. Thus, we used the NADPH-dependent reduction of NBT as a quantitative measure of total superoxide production together with ultrastructural histochemistry studies with cerium chloride to show that anion superoxide is formed and progressively accumulates on the $\mathrm{BcCV}$ membrane, in parallel with the observed kinetics of NADPH oxidase subunit assembly.

The specific mechanism utilized by $B$. cenocepacia to delay the recruitment/assembly of a functional NADPH oxidase complex on its phagosomal membrane is unknown. In other bacteria such as Salmonella enterica type III secreted effectors mediate the exclusion of NADPH oxidase components from the Salmonella-containing vacuole (Gallois et al., 2001; Vazquez-Torres et al., 2000). The effectors responsible for this exclusion are believed to act through tumour necrosis factor receptor p55 (VazquezTorres \& Fang, 2001). We have previously demonstrated that a polar mutation introduced in the first gene of the $B$. cenocepacia J2315 type III secretion gene cluster does not abolish the BcCV maturation delay (Lamothe et al., 2007), arguing that type III secreted effectors are likely not involved in the delay of NADPH oxidase assembly. Recently, it has been reported that type IV secretion is required for the intracellular survival of B. cenocepacia K562 (Sajjan et al., 2008), a strain clonally related to J2315 (Mahenthiralingam et al., 2000), suggesting the possibility that an unidentified type IV secreted effector may be involved in the $\mathrm{BcCV}$ maturation delay. We have also observed that B. cenocepacia possesses a type VI secretory system that causes disruptions in the actin cytoskeleton (Aubert et al., 2008). There is evidence that components of the NADPH complex, including $\mathrm{p} 40^{\text {phox }}$, associate with the actin cytoskeleton (Chen et al., 2007). Therefore, we are 
(a)

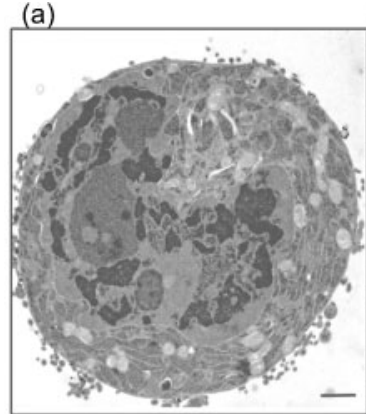

(b)

(c)
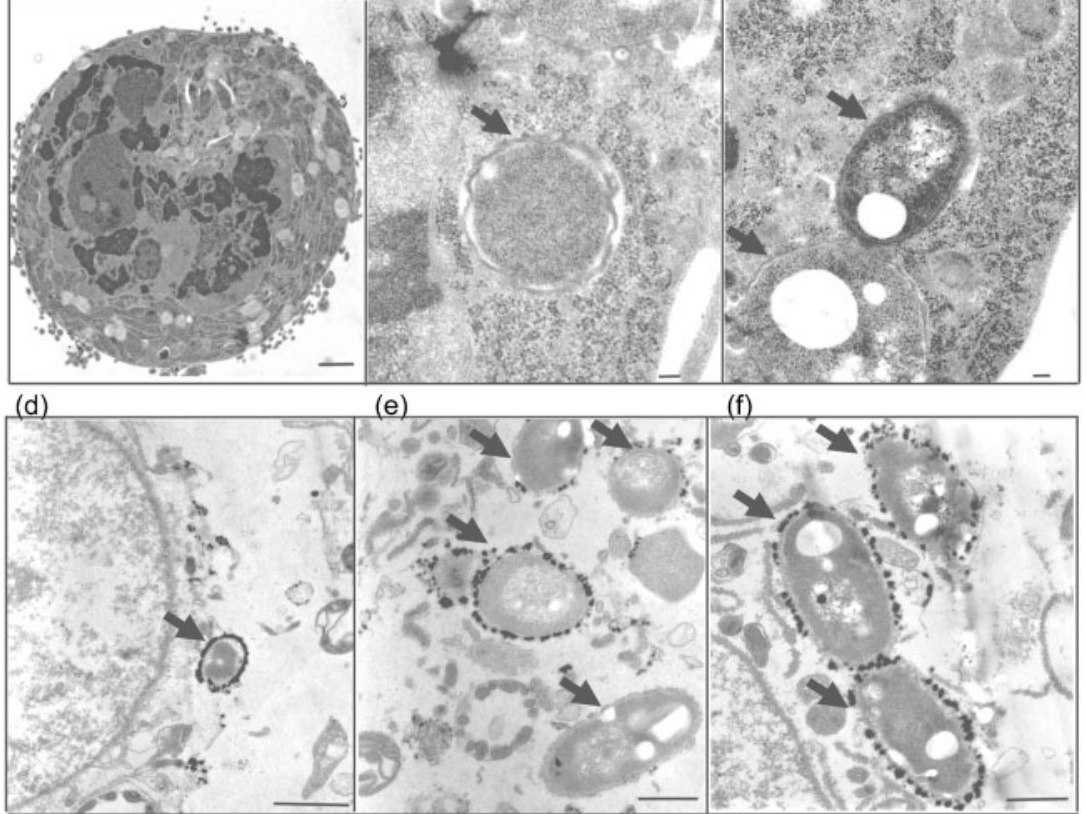

(e)

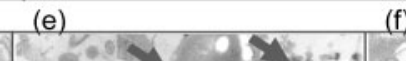

(f)

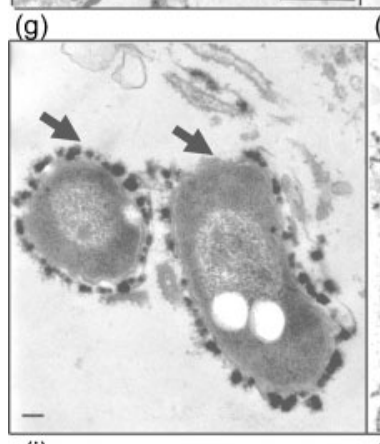

(j) (k)

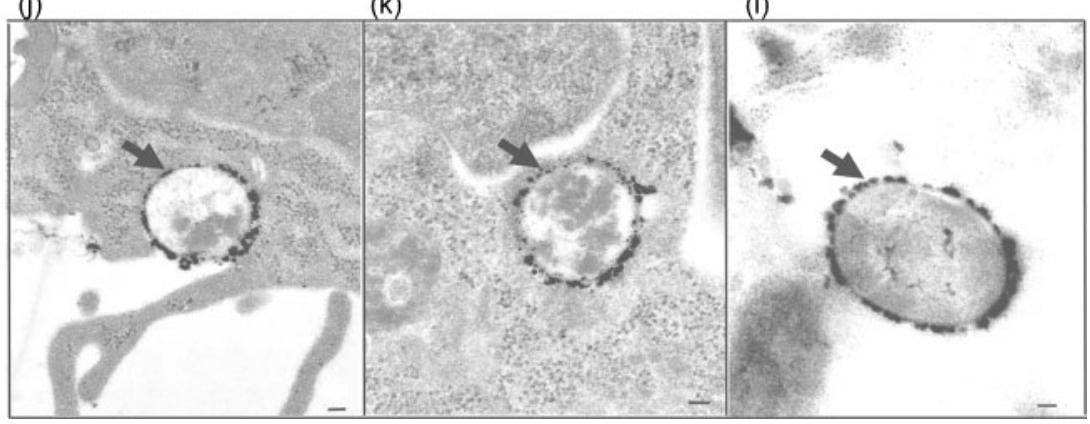

Fig. 6. Visualization of NADPH oxidase activity in B. cenocepacia-infected RAW 264.7 macrophages treated with cerium chloride as described in Methods. Deposits of electrondense cerium perhydroxide indicate superoxide formation, suggesting NADPH oxidase activity. Arrows point to the membrane of bacteria-containing vacuoles. Macrophages infected with viable $B$. cenocepacia were examined at $2 \mathrm{~h}(\mathrm{a}-\mathrm{c}), 4 \mathrm{~h}(\mathrm{~d}-\mathrm{f})$, and $6 \mathrm{~h}(\mathrm{~g}-\mathrm{i})$ post-infection, respectively. Macrophages infected with $E$. coli were examined at $1 \mathrm{~h}$ post-infection ( $j-k)$. Macrophages exposed to heat-inactivated $B$. cenocepacia were examined at $2 \mathrm{~h}$ post-infection. Scale bars are as follows: (a), (d) and (h), $1 \mu \mathrm{m}$; (b), (c), (i), (j), (k) and (l), $0.1 \mu \mathrm{m} ;(\mathrm{e})$, (f) and (g), $0.5 \mu \mathrm{m}$. currently investigating whether type VI and perhaps also type IV secreted bacterial effectors could be involved in the NADPH oxidase assembly delay. Other researchers have noticed that $B$. cenocepacia can cause cell death of neutrophils from patients with CGD (Bylund et al., 2005) and also human dendritic cells (Macdonald \& Speert, 2008). Therefore, an alternative possibility to explain our results is that the intracellular infection may induce cell death in macrophages and the mislocalization of the NADPH oxidase may be associated with this process. However, macrophages do not show any evidence of loss of viability as determined by trypan blue exclusion assays and lactic acid dehydrogenase release during the $6 \mathrm{~h}$ time- course of our experiments (L. S. Saini \& M. A. Valvano, unpublished).

Little is known regarding whether there is any link between the CFTR defect and the increased susceptibility of CF patients to opportunistic pathogens such as B. cenocepacia. Recently, it was suggested that phagolysosomes in alveolar macrophages have a CFTR-dependent constitutive defect in acidification that could lead to impaired bactericidal activity (Di et al., 2006). In contrast, a detailed analysis using fluorescence ratio imaging to measure the endosomal $\mathrm{pH}$ against an internal standard convincingly demonstrated that phagolysosomal acidification in macrophages is 
CFTR-independent (Haggie \& Verkman, 2007). It has also been demonstrated that inhibition of CFTR activity is responsible for the onset of the inflammatory cascade in the CF lung (Perez et al., 2007). Our independent studies using a pair of $c f t r$-null and $c f t r^{+/+}$murine macrophages support the notion that CFTR is not directly involved in phagosomal acidification (Lamothe \& Valvano, 2008). However, we have also observed that in cftr-null macrophages as well as in normal macrophages treated with the CFTR $_{\text {inh }}-172$ the BcCVs exhibit an even more prolonged maturation delay that is only manifested upon infection with live B. cenocepacia (Lamothe \& Valvano, 2008). Here, we examined whether the status of CFTR affects the association of the NADPH oxidase with BcCVs. The results clearly show that in macrophages treated with $\mathrm{CFTR}_{\text {inh }}-172$ there is a further delay in NADPH oxidase assembly on the membrane of the BcCV. The prolonged delay in colocalization of the NADPH oxidase at the phagosomal membrane in the presence of the CFTR inhibitor did not occur when macrophages were infected with either heatinactivated B. cenocepacia or E. coli controls, suggesting a specific interaction between CFTR and a B. cenocepaciaspecific component.

In conclusion, the experiments reported here add new knowledge about the characteristics of the intracellular infection of macrophages by $B$. cenocepacia by showing that in addition to reduced acidification and delayed fusion with late phagolysosomal markers (Lamothe et al., 2007), $\mathrm{BcCVs}$ exhibit a delay in the normal assembly of a functional NADPH oxidase complex on their membrane. Our experiments also support a role for CFTR in the clearance of the intracellular infection by $B$. cenocepacia, which might help explain why CF patients are preferentially infected by Burkholderia species over a myriad of other antibiotic multi-resistant environmental opportunistic pathogens.

\section{ACKNOWLEDGEMENTS}

The authors thank R. Flannagan for the construction of pRedCm4. The transmission electron microscopy studies were performed in the Department of Microbiology and Immunology Transmission Electron Microscopy Facility. This work was supported by an operating grant from the Canadian Cystic Fibrosis Foundation. A Post-Doctoral Fellowship from the Canadian Cystic Fibrosis Foundation supported K.E. K. M.A.V. holds a Canada Research Chair in Infectious Diseases and Microbial Pathogenesis.

\section{REFERENCES}

Allen, L. A., Beecher, B. R., Lynch, J. T., Rohner, O. V. \& Wittine, L. M. (2005). Helicobacter pylori disrupts NADPH oxidase targeting in human neutrophils to induce extracellular superoxide release. J Immunol 174, 3658-3667.

Aubert, D. F., Flannagan, R. S. \& Valvano, M. A. (2008). A novel sensor kinase-response regulator hybrid controls biofilm formation and virulence in Burkholderia cenocepacia. Infect Immun 76, 19791991.
Bokoch, G. M. \& Diebold, B. A. (2002). Current molecular models for NADPH oxidase regulation by Rac GTPase. Blood 100, 2692-2696.

Burns, J. L., Jonas, M., Chi, E. Y., Clark, D. K., Berger, A. \& Griffith, A. (1996). Invasion of respiratory epithelial cells by Burkholderia (Pseudomonas) cepacia. Infect Immun 64, 4054-4059.

Bylund, J., Campsall, P. A., Ma, R. C., Conway, B. A. \& Speert, D. P. (2005). Burkholderia cenocepacia induces neutrophil necrosis in chronic granulomatous disease. J Immunol 174, 3562-3569.

Carlyon, J. A. \& Fikrig, E. (2006). Mechanisms of evasion of neutrophil killing by Anaplasma phagocytophilum. Curr Opin Hematol 13, 28-33.

Chen, J., He, R., Minshall, R. D., Dinauer, M. C. \& Ye, R. D. (2007). Characterization of a mutation in the Phox homology domain of the NADPH oxidase component $440^{\text {phox }}$ identifies a mechanism for negative regulation of superoxide production. J Biol Chem 282, 30273-30284.

Cheng, S. H., Gregory, R. J., Marshall, J., Paul, S., Souza, D. W., White, G. A., O'Riordan, C. R. \& Smith, A. E. (1990). Defective intracellular transport and processing of CFTR is the molecular basis of most cystic fibrosis. Cell 63, 827-834.

Chiu, C. H., Ostry, A. \& Speert, D. P. (2001). Invasion of murine respiratory epithelial cells in vivo by Burkholderia cepacia. J Med Microbiol 50, 594-601.

Coenye, T. \& Vandamme, P. (2003). Diversity and significance of Burkholderia species occupying diverse ecological niches. Environ Microbiol 5, 719-729.

De Leo, F. R., Ulman, K. V., Davis, A. R., Jutila, K. L. \& Quinn, M. T. (1996). Assembly of the human neutrophil NADPH oxidase involves binding of $\mathrm{p} 67^{\text {phox }}$ and flavocytochrome $b$ to a common functional domain in $47^{\text {phox }}$. J Biol Chem 271, 17013-17020.

Di, A., Brown, M. E., Deriy, L. V., Li, C., Szeto, F. L., Chen, Y., Huang, P., Tong, J., Naren, A. P. \& other authors (2006). CFTR regulates phagosome acidification in macrophages and alters bactericidal activity. Nat Cell Biol 8, 933-944.

Dinauer, M. C. \& Orkin, S. H. (1992). Chronic granulomatous disease. Annu Rev Med 43, 117-124.

Fang, F. C. (2004). Antimicrobial reactive oxygen and nitrogen species: concepts and controversies. Nat Rev Microbiol 2, 820-832.

Gallois, A., Klein, J. R., Allen, L. A., Jones, B. D. \& Nauseef, W. M. (2001). Salmonella pathogenicity island 2-encoded type III secretion system mediates exclusion of NADPH oxidase assembly from the phagosomal membrane. J Immunol 166, 5741-5748.

Guide, S. V., Stock, F., Gill, V. J., Anderson, V. L., Malech, H. L., Gallin, J. I. \& Holland, S. M. (2003). Reinfection, rather than persistent infection, in patients with chronic granulomatous disease. J Infect Dis 187, 845-853.

Haggie, P. M. \& Verkman, A. S. (2007). Cystic fibrosis transmembrane conductance regulator-independent phagosomal acidification in macrophages. J Biol Chem 282, 31422-31428.

Han, C. H., Freeman, J. L., Lee, T., Motalebi, S. A. \& Lambeth, J. D. (1998). Regulation of the neutrophil respiratory burst oxidase. Identification of an activation domain in $\mathrm{p} 67^{\text {phox }}$. J Biol Chem 273, 16663-16668.

Heyworth, P. G., Curnutte, J. T., Nauseef, W. M., Volpp, B. D., Pearson, D. W., Rosen, H. \& Clark, R. A. (1991). Neutrophil nicotinamide adenine dinucleotide phosphate oxidase assembly. Translocation of $\mathrm{p} 47$-phox and $\mathrm{p} 67$ - $p$ hox requires interaction between p47-phox and cytochrome $b_{558}$. J Clin Invest 87, 352-356.

Holt, P. G., Strickland, D. H., Wikstrom, M. E. \& Jahnsen, F. L. (2008). Regulation of immunological homeostasis in the respiratory tract. Nat Rev Immunol 8, 142-152. 
Isles, A., Maclusky, I., Corey, M., Gold, R., Prober, C., Fleming, P. \& Levison, H. (1984). Pseudomonas cepacia infection in cystic fibrosis: an emerging problem. J Pediatr 104, 206-210.

Keig, P. M., Ingham, E., Vandamme, P. A. \& Kerr, K. G. (2002). Differential invasion of respiratory epithelial cells by members of the Burkholderia cepacia complex. Clin Microbiol Infect 8, 47-49.

Keith, K. E. \& Valvano, M. A. (2007). Characterization of SodC, a periplasmic superoxide dismutase from Burkholderia cenocepacia. Infect Immun 75, 2451-2460.

Keith, K. E., Killip, L., He, P., Moran, G. H. \& Valvano, M. A. (2007). Burkholderia cenocepacia C5424 produces a pigment with antioxidant properties using a homogentisate intermediate. J Bacteriol 189, 90579065.

Kuribayashi, F., Nunoi, H., Wakamatsu, K., Tsunawaki, S., Sato, K., Ito, T. \& Sumimoto, H. (2002). The adaptor protein $\mathrm{p} 40^{\text {phox }}$ as a positive regulator of the superoxide-producing phagocyte oxidase. EMBO J 21, 6312-6320.

Lamothe, J. \& Valvano, M. A. (2008). Burkholderia cenocepaciainduced delay of acidification and phagolysosomal fusion in cystic fibrosis transmembrane conductance regulator (CFTR)-defective macrophages. Microbiology 154, 3825-3834.

Lamothe, J., Thyssen, S. \& Valvano, M. A. (2004). Burkholderia cepacia complex isolates survive intracellularly without replication within acidic vacuoles of Acanthamoeba polyphaga. Cell Microbiol 6, $1127-1138$.

Lamothe, J., Huynh, K. K., Grinstein, S. \& Valvano, M. A. (2007). Intracellular survival of Burkholderia cenocepacia in macrophages is associated with a delay in the maturation of bacteria-containing vacuoles. Cell Microbiol 9, 40-53.

Landers, P., Kerr, K. G., Rowbotham, T. J., Tipper, J. L., Keig, P. M., Ingham, E. \& Denton, M. (2000). Survival and growth of Burkholderia cepacia within the free-living amoeba Acanthamoeba polyphaga. Eur J Clin Microbiol Infect Dis 19, 121-123.

Lefebre, M. D. \& Valvano, M. A. (2002). Construction and evaluation of plasmid vectors optimized for constitutive and regulated gene expression in Burkholderia cepacia complex isolates. Appl Environ Microbiol 68, 5956-5964.

Lipuma, J. J. (2005). Update on the Burkholderia cepacia complex. Curr Opin Pulm Med 11, 528-533.

Lodge, R. \& Descoteaux, A. (2006). Phagocytosis of Leishmania donovani amastigotes is Rac1 dependent and occurs in the absence of NADPH oxidase activation. Eur J Immunol 36, 2735-2744.

Lodge, R., Diallo, T. O. \& Descoteaux, A. (2006). Leishmania donovani lipophosphoglycan blocks NADPH oxidase assembly at the phagosome membrane. Cell Microbiol 8, 1922-1931.

Ma, T., Thiagarajah, J. R., Yang, H., Sonawane, N. D., Folli, C., Galietta, L. J. \& Verkman, A. S. (2002). Thiazolidinone CFTR inhibitor identified by high-throughput screening blocks cholera toxin-induced intestinal fluid secretion. J Clin Invest 110, 1651-1658.

Macdonald, K. L. \& Speert, D. P. (2008). Differential modulation of innate immune cell functions by the Burkholderia cepacia complex: Burkholderia cenocepacia but not Burkholderia multivorans disrupts maturation and induces necrosis in human dendritic cells. Cell Microbiol 10, 2138-2149.

Mahenthiralingam, E., Coenye, T., Chung, J. W., Speert, D. P., Govan, J. R., Taylor, P. \& Vandamme, P. (2000). Diagnostically and experimentally useful panel of strains from the Burkholderia cepacia complex. J Clin Microbiol 38, 910-913.

Mahenthiralingam, E., Urban, T. A. \& Goldberg, J. B. (2005). The multifarious, multireplicon Burkholderia cepacia complex. Nat Rev Microbiol 3, 144-156.
Mahenthiralingam, E., Baldwin, A. \& Dowson, C. G. (2008). Burkholderia cepacia complex bacteria: opportunistic pathogens with important natural biology. J Appl Microbiol 104, 1539-1551.

Maloney, K. E. \& Valvano, M. A. (2006). The $m g t C$ gene of Burkholderia cenocepacia is required for growth under magnesium limitation conditions and intracellular survival in macrophages. Infect Immun 74, 5477-5486.

Marolda, C. L., Hauröder, B., John, M. A., Michel, R. \& Valvano, M. A. (1999). Intracellular survival and saprophytic growth of isolates from the Burkholderia cepacia complex in free-living amoebae. Microbiology 145, 1509-1517.

Martin, D. W. \& Mohr, C. D. (2000). Invasion and intracellular survival of Burkholderia cepacia. Infect Immun 68, 24-29.

Minakami, R. \& Sumimotoa, H. (2006). Phagocytosis-coupled activation of the superoxide-producing phagocyte oxidase, a member of the NADPH oxidase (Nox) family. Int J Hematol 84, 193-198.

Mott, J., Rikihisa, Y. \& Tsunawaki, S. (2002). Effects of Anaplasma phagocytophila on NADPH oxidase components in human neutrophils and HL-60 cells. Infect Immun 70, 1359-1366.

Nakashima, T., Iwashita, T., Fujita, T., Sato, E., Niwano, Y., Kohno, M., Kuwahara, S., Harada, N., Takeshita, S. \& Oda, T. (2008). A prodigiosin analogue inactivates NADPH oxidase in macrophage cells by inhibiting assembly of $\mathrm{p} 47^{\text {phox }}$ and Rac. J Biochem 143, 107-115.

Nauseef, W. M., Volpp, B. D., McCormick, S., Leidal, K. G. \& Clark, R. A. (1991). Assembly of the neutrophil respiratory burst oxidase. Protein kinase $\mathrm{C}$ promotes cytoskeletal and membrane association of cytosolic oxidase components. J Biol Chem 266, 5911-5917.

O’Donnell, B. V., Tew, D. G., Jones, O. T. \& England, P. J. (1993). Studies on the inhibitory mechanism of iodonium compounds with special reference to neutrophil NADPH oxidase. Biochem J 290, 41-49.

Perez, A., Issler, A. C., Cotton, C. U., Kelley, T. J., Verkman, A. S. \& Davis, P. B. (2007). CFTR inhibition mimics the cystic fibrosis inflammatory profile. Am J Physiol Lung Cell Mol Physiol 292, L383-L395.

Rook, G. A., Steele, J., Umar, S. \& Dockrell, H. M. (1985). A simple method for the solubilisation of reduced NBT, and its use as a colorimetric assay for activation of human macrophages by gammainterferon. J Immunol Methods 82, 161-167.

Saini, L. S., Galsworthy, S. B., John, M. A. \& Valvano, M. A. (1999). Intracellular survival of Burkholderia cepacia complex isolates in the presence of macrophage cell activation. Microbiology 145, 3465-3475.

Sajjan, U. S., Yang, J. H., Hershenson, M. B. \& LiPuma, J. J. (2006). Intracellular trafficking and replication of Burkholderia cenocepacia in human cystic fibrosis airway epithelial cells. Cell Microbiol 8, 14561466.

Sajjan, S. U., Carmody, L. A., Gonzalez, C. F. \& LiPuma, J. J. (2008). A type IV secretion system contributes to intracellular survival and replication of Burkholderia cenocepacia. Infect Immun 76, 5447-5455.

Saldías, M. S., Lamothe, J., Wu, R. \& Valvano, M. A. (2008). Burkholderia cenocepacia requires the RpoN sigma factor for biofilm formation and intracellular trafficking within macrophages. Infect Immun 76, 1059-1067.

Segal, A. W. (2005). How neutrophils kill microbes. Annu Rev Immunol 23, 197-223.

Takeya, R. \& Sumimoto, H. (2003). Molecular mechanism for activation of superoxide-producing NADPH oxidases. Mol Cells 16, 271-277.

Telek, G., Scoazec, J. Y., Chariot, J., Ducroc, R., Feldmann, G. \& Rozé, C. (1999). Cerium-based histochemical demonstration of oxidative stress in taurocholate-induced acute pancreatitis in rats. A confocal laser scanning microscopic study. J Histochem Cytochem 47, $1201-1212$. 
Ueyama, T., Tatsuno, T., Kawasaki, T., Tsujibe, S., Shirai, Y., Sumimoto, H., Leto, T. L. \& Saito, N. (2007). A regulated adaptor function of $\mathrm{p} 40^{\text {phox }}$ : distinct $\mathrm{p} 67^{\text {phox }}$ membrane targeting by $\mathrm{p} 40^{\text {phox }}$ and by $4^{\text {phox }}$. Mol Biol Cell 18, 441-454.

Valvano, M. A. (2006). Infections by Burkholderia species: the psychodramatic life of an opportunistic pathogen. Future Microbiol 1, 145149.

Valvano, M. A., Keith, K. E. \& Cardona, S. T. (2005). Survival and persistence of opportunistic Burkholderia species in host cells. Curr Opin Microbiol 8, 99-105.

Vazquez-Torres, A. \& Fang, F. C. (2001). Oxygen-dependent antiSalmonella activity of macrophages. Trends Microbiol 9, 29-33.
Vazquez-Torres, A., Xu, Y., Jones-Carson, J., Holden, D. W., Lucia, S. M., Dinauer, M. C., Mastroeni, P. \& Fang, F. C. (2000). Salmonella pathogenicity island 2-dependent evasion of the phagocyte NADPH oxidase. Science 287, 1655-1658.

Vignais, P. V. (2002). The superoxide-generating NADPH oxidase: structural aspects and activation mechanism. Cell Mol Life Sci 59, 1428-1459.

Waterman, S. R. \& Holden, D. W. (2003). Functions and effectors of the Salmonella pathogenicity island 2 type III secretion system. Cell Microbiol 5, 501-511.

Edited by: P. Cornelis 